\title{
Staatliche Gemeinschaft und Staatengemeinschaft
}

Grundgesetz und Europäische Union im internationalen öffentlichen Recht der Gegenwart

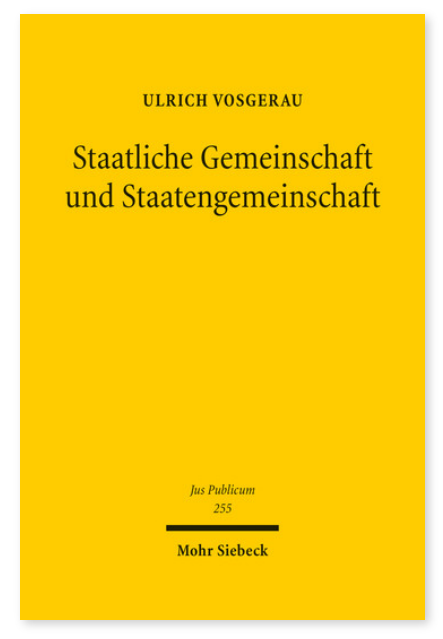

2016. XXIII, 401 Seiten. JusPubl 255

ISBN 978-3-16-152436-3

DOI 10.1628/978-3-16-152436-3

eBook PDF 119,00€

ISBN 978-3-16-152435-6

Leinen $119,00 €$
Dem Grundgesetz ist eine verfassungsrechtliche Grundentscheidung für die internationale Zusammenarbeit zu entnehmen, und auch das Demokratieprinzip des Grundgesetzes soll erst im Lichte der Eingliederung des durch das Grundgesetz verfassten Staates in die Staatengemeinschaft zu verstehen sein. Gleichzeitig soll es sich aber bei dieser Grundentscheidung nicht um eine Unterwerfung unter fremde Mächte handeln, sondern um eine freiwillige, gegenseitige und gleichberechtigte Bindung, die den Frieden sichert und die politischen Gestaltungsmöglichkeiten durch gemeinsames koordiniertes Handeln stärkt. Was aber bedeuten diese allgemein akzeptierten verfassungsrechtlichen Programmsätze in der Sache, und wie hat man sich die Rechtsnatur dieses Eingliederungsverhältnisses eigentlich vorzustellen? Zur Beantwortung dieser Fragen entwickelt Ulrich Vosgerau eine grundlegende Geltungstheorie des Völker- und Europarechts im Geiste des Selbstbestimmungsrechts der Völker als »idée directrice".

Ulrich Vosgerau Studium der Rechtswissenschaft an der Universität Passau und der Albert-Ludwigs-Universität Freiburg i.Br. Stipendiat der Studienstiftung des deutschen Volkes. Referendariat beim KG Berlin und an der Hochschule für Verwaltungswissenschaften in Speyer; seit 2004 Rechtsanwalt in Berlin; 2006 Promotion (Albert-Ludwigs-Universität Freiburg i.Br.); seit 2006 wissenschaftlicher Mitarbeiter; 2007-14 Akademischer Rat am Seminar für Staatsphilosophie und Rechtspolitik der Universität zu Köln, anschließend bis 2015 fakultätsunmittelbarer Akademischer Rat mit wissenschaftlichen Aufgaben; 2012 Habilitation; seither Lehrstuhlvertretungen an der LMU München, der Leibniz Universität Hannover, der Universität Passau und der Martin-Luther-Universität Halle-Wittenberg.

Jetzt bestellen:

https://mohrsiebeck.com/buch/staatliche-gemeinschaft-und-staatengemeinschaft-9783161524363?no_cache=1 order@mohrsiebeck.com

Telefon: +49 (0)7071-923-17

Telefax: $+49(0) 7071-51104$ 